\title{
Collaborative Meaning-Making in Arts-Based Research: Data Interpretation with an Artist, a Physician, and an Art Historian
}

\author{
Kaisu Koski ${ }^{1}$ \\ Research Centre for Performative Processes, HKU University of the Arts Utrecht, Netherlands \\ Centre for Practice as Research in Theatre, University of Tampere, Finland \\ kaisu.koski@staff.uta.fi \\ Fenna Heyning \\ Association of Tertiary Medical Teaching Hospitals, Utrecht, Netherlands \\ f.heyning@stz.nl \\ Robert Zwijnenberg \\ Centre for the Arts in Society, Faculty of Humanities, Leiden University, Netherlands \\ R.Zwijnenberg@hum.leidenuniv.nl
}

\begin{abstract}
This article discusses collaborative meaning-making in arts-based research. It introduces a project in which an artist-researcher invited a physician and an art historian to help to interpret medical students' hand-made drawings of the female reproductive system and the conception process. The authors elaborate on different viewpoints and improvisation during the data interpretation, and discuss how these were founded on, and disrupted, their professional roles in various ways. The article discusses how the different interpretations of the students' drawings complemented or conflicted with each other. It also discusses the use of associations and humor in these interpretations, and the experiences of emotional discomfort during the process.
\end{abstract}

Keywords: arts-based research, collaborative meaning-making, anatomical drawing, female reproductive system, medical student, playful association, humor, embarrassment

\footnotetext{
${ }^{1}$ Biographical statements: Kaisu Koski is an artist-researcher whose art practice is intertwined with academic research. Kaisu's postdoctoral research project (2011-2013) explored various representations of the body in medical education, and she conducted fellowships in the University of Alberta and Plymouth University medical schools. She currently carries out an Academy Research Fellow project (2015-2020), funded by the Academy of Finland, in the Centre for Practice as Research in Theatre in the University of Tampere. This project develops arts-based educational videos for medical curricula in Finland, Denmark and the U.S.
}

Fenna Heyning is trained as a medical specialist in internal medicine. She wrote her PhD on primary lymphoma of bone. Since 2014 she switched from treating the individual patient to working to improve the system of quality and safety of patient care. In her current job as the director of a tertiary hospital association she focusses on clinical leadership and shared decision-making. She is the founder of an art foundation, stichting Genees-Kunst, or "the art of healing," which aims to help bone marrow transplant patients, kept in isolation for extended periods of time by bringing them into contact with artists. Based on these dialogues with the patients the artists make works of art to help the patients in their healing processes.

Robert Zwijnenberg is professor of Art and Science Interactions (Faculty of Humanities, Leiden University) and director of The Arts and Genomics Centre (http://www.artsgenomics.org). Trained in civil engineering and philosophy, he received a $\mathrm{PhD}$ in philosophy from the University of Amsterdam. His research focus is on the role of contemporary art in academic and public debates on the implications of the life sciences. 


\section{Introduction}

This article examines collaborative meaning-making in an arts-based research project in which members of three different disciplines-the inviting artist, a physician, and an art historian-were involved in the interpretation of medical students' drawings of the female reproductive system. It elaborates on how the drawings' meanings were elicited collaboratively, simultaneously introducing the projects' main interpretations of the data. The writing style reflects the multiple disciplinary and character viewpoints by combining atypically first-person singular and plural modalities, as well as the third-person point of view. For instance, next to my (Kaisu's) standpoint as the principal investigator-artist, and the general description of the setting and context, the three of us reflect on the process with a shared voice.

As the initiator of the project, I will first introduce the project and its background. Arts-based research methods are used in health care (education) research at all stages of inquiry, particularly in data collection or stimulation, and as a form of dissemination (Cox et al. 2010; Casey, 2009). Unlike in much qualitative health research, however, where creativity means expanding social science methods with the arts (Hunter, Lusardi, Zucker, Jacelon \& Chandler, 2002), this project was essentially inspired by my identity and practice as a visual-performative artist, expanding the arts-based data analysis by inviting collaborators from other disciplines. The resulting animation Not to scale at all (Koski, 2014) $)^{2}$ disseminates not only selected key findings of the study, but exposes the collaborative data analysis process. The aim of this article is to articulate the methodssuch as improvisation, role-playing, and "mind-reading"-that are embedded in this process, as well as the experiences of embarrassment and humor that emerged from these methods.

Arts-based health research projects typically avoid misrepresentation of the participants' data while still fully appreciating the voices of emotion (Hodgins \& Boydell, 2013) and aesthetic interpretation in collecting and discussing the data through art. The artist-researcher's artistic medium and aesthetics have a great influence on the resulting artworks. While many arts-based health research projects minimize the relevance of aesthetic interpretation and pursue "naturalism" in the resulting artworks (Gray \& Kontos, 2015), the postdramatic style of performance (see Lehmann, 2006) used in this project emerged from my "signature" as an artist (since I am embedded in the contemporary arts scene in Europe), instead of deriving from a search for objectivity. Working with the research participants, however, has influenced my artistic decision-making activities during the process. The personal connection with the medical students has heightened my need to treat the drawings with respect: as extensions of the students' thoughts. In this view, the project emerges from the medical students' generosity and trust. I thus consider it significant, in this type of arts-based research study, that the artist-researcher interacts with the participants in a personal manner, instead of being invited to participate in a research project at a later stage.

While creating intriguing art was one of the expectations for this project (as it is for most artists), the parameters of doing so was and should be determined by respect for the medical students and their drawings. Yet, this respect was challenged by the collaborative

\footnotetext{
2 The animation Not to scale at all can be viewed at: https://ualberta.aviaryplatform.com/r/fx73t9f40p
} 
meaning-making process and the emerging artwork in several ways. The authenticity of the participants' data, for instance, did not automatically parallel the artists' authenticity or their loyalty to their practice. I have elsewhere written about such ethical tensions (Koski 2012), and about how an artwork seems to develop its own voice during the process and "demand" particular kinds of materials and decisions from the artist. This article will explore such tensions that arise between making dramaturgical decisions and staging the vulnerability that was present in the collaborators' dialogues.

The data interpretation in this study consists of roughly of two phases: 1) the initial classification of the students' drawings, conducted by the artist-researcher, and 2) the collaborative data interpretation, including the viewpoints of an art historian and a physician, to elaborate on possible reasons behind the initial findings. In the data interpretation the collaborators were invited to represent a particular role or character (similar to themselves) in a staged setting: those of a physician and an art historian. In this staging I identify as and perform the role of an artist. The article thus takes a dramaturgical and performative approach, not only considering the data interpretation conversations to be performative, but considering the entire collaborative process as manifesting Erving Goffman's (1959) metaphor of identity as performance. This means that the starting point for the collaboration was a working consensus of different professionals (Silver, Sabini \& Parrott, 1987, p. 48), performed as three distinct characters. These initial dispositions were created in order to stimulate argumentation from multiple viewpoints, thus increasing the likelihood for different readings of the drawings.

Paralleling Goffman's (1959) thinking, the inquiry involved adaptations of performative analysis (Riessman, 2003): the drawings were considered to be performing aspects of the students' identities through "characters" and "settings" that are portrayed (or absent) on paper. Furthermore, the students' identities were interpreted through the characters we performed, involving an underlying expectancy that the conversations delivered material for a research-based artwork and an arts-based dissemination of the project: the animation Not to scale at all (Koski, 2014). The meaning-making in this animation can thus be considered to be a performance from two viewpoints: first, three of us are performing our professional identities in the "here-and-now" work situation, and second, we are performing in front of the imagined future audience of the animation. As an artist-researcher, I functioned in this process first as a director of these performative conversations, stimulating different modes of talking both "in" and "out" of character (Goffman, 1959), and later as a composer in ordering elements of them into an animation narrative.

The article consists of two parts: as the principal investigator-artist, I first describe the study background and architecture of the two data interpretation conversations under examination in more detail. In the second part, three of us together discuss various aspects of the collaborative process: 1) Different readings of the drawings, considering our professional viewpoints; 2) Playful, improvisatory associations as stimuli for our interpretations; and 3) Experiences of emotional discomfort during the collaborative process. The article investigates how each of these aspects relates to the establishment or disruption of a performance of a particular professional role, and how the arts-based methods such as improvisation stimulate the dropping of, or confusion of characters. The article considers the differences, playful associations, and emotional discomforts as fruitful characteristics of a collaborative arts-based research process, instead of viewing them as something to be avoided. 


\section{Study Background}

The collaboration emerged as part of my postdoctoral research project. I collected 63 anonymous first-year medical students' drawings from the Plymouth University Peninsula School of Medicine in October of 2012. After an "Induction" lecture, as part of the introductory period of the curriculum, the students were invited to visualize the female reproductive system and the conception process by creating a hand-made drawing in four minutes. I have elsewhere (Koski, 2014) described the procedure of collecting the drawings, including the initial data analysis of the drawings' anatomical accuracy and the classification of the fe/male drawing differences through semiotic concepts. During my fellowship at the medical school, I also investigated ways that study materials portray the female reproductive system. Most contemporary anatomical visualizations belong to a monological discourse of medical diagnoses (Frank, 2005, p. 967), and they do not leave room for multiple interpretations. The representations of the female reproduction system, in particular, are predominantly portrayed through the metaphor of a signaling system, in which the female anatomy (until menopause) is thought of as being "created for the work it can do," i.e. reproduction (Martin, 1992). The students' drawings, however, had not yet been completely assimilated to the sterile imageries of anatomical atlases. In the study described here, the drawings were viewed as representations of the visual culture in medical education, containing emotional and cultural values through seemingly innocent anatomy.

Related to my initial findings, and the multiple voices present in the students' drawing data, I felt that reflecting the differences in the female and male drawings from my viewpoint alone would have made the artwork too one-dimensional. There thus arose a need to invite interdisciplinary viewpoints to generate dialogue on the drawings' meanings. I imagined that the well-developed visual sensibility of an art historian, as well as the expertise of a physician, would create interesting perspectives. In addition, including both male and female expert perspectives seemed necessary. Robert Zwijnenberg, Professor of art history at Leiden University, specializes not only in da Vinci's (female) anatomical drawings, but also in contemporary interactions between art and science. Fenna Heyning, MD PhD, in turn, was invited to the project due to her medical expertise, but also because of her viewpoint as a woman, and her interest in the portrayal of the human body through art.

At the time of the conversations there was no plan to view the audio recordings as research data, or as materials for future collaboration in the form of an article. However, since only a few of our key findings were embedded in the animation as a voice-over dialogue, and the selection of these findings in the recordings was made only by me, I felt the need to expand our reflection on the findings to be collaborative. By focusing on cogenerating stories from the students' drawings, the project manifests a principle of perpetual generation: it is here considered that the meaning of any present story, including those of the students' drawings, depends on the future stories they will generate (Frank, 2005, p. 967).

The study process (Figure 1) began with me collecting the drawings and conducting an initial analysis of them. I then discussed the drawings and my findings separately with Robert and Fenna. After that, I edited segments of our audiotaped conversations into an animation soundtrack, thus forming a narrative together with the selected students' 
drawings. The resulting animation was later screened for Robert's students. Lastly, this article provides a platform for our reflections on this process.

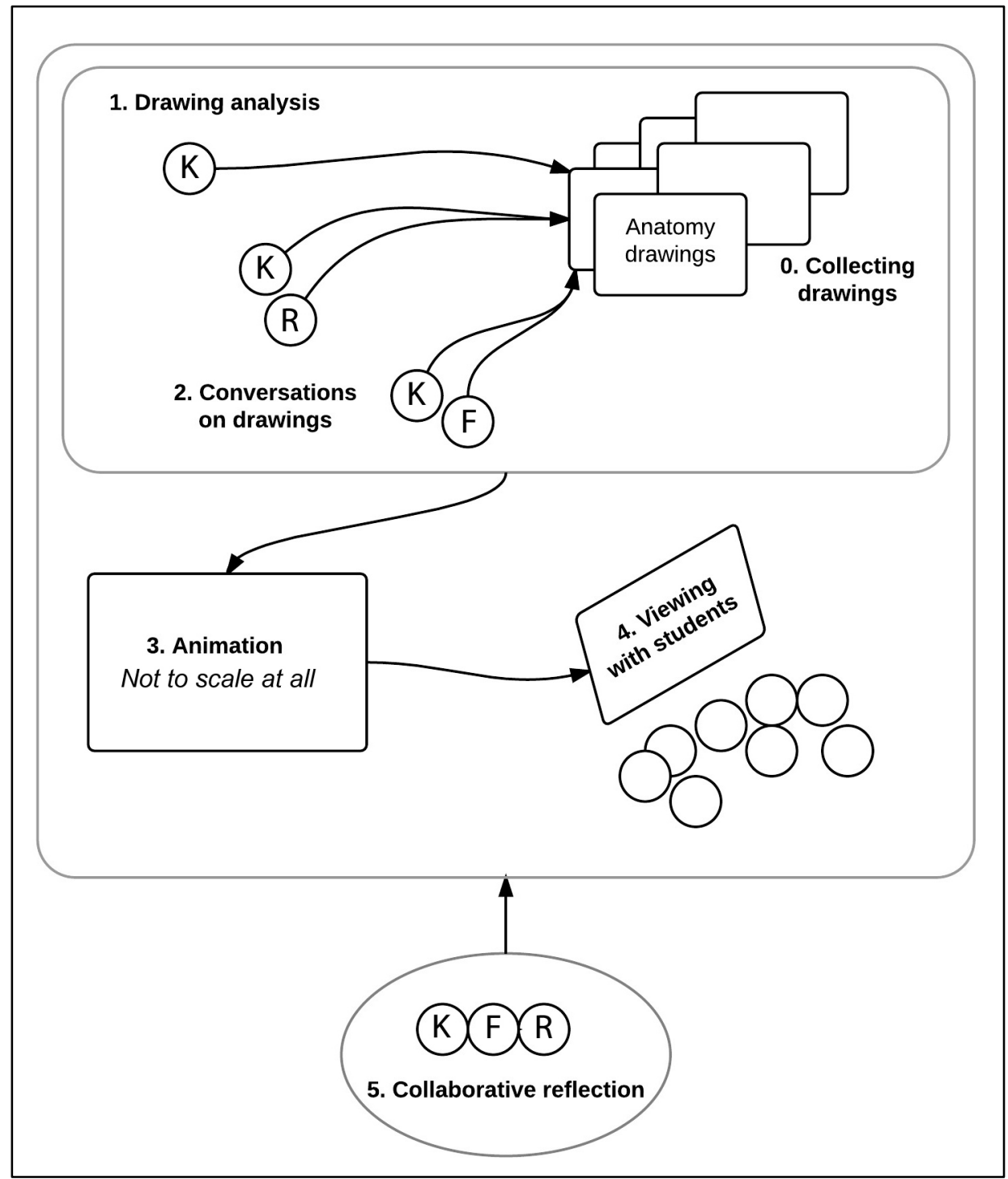

Figure 1. The study process.

\section{Conversation Procedure: Settings and Character Relationships}

At the onset of the conversations I introduced my initial findings on the drawings, and how I viewed them in light of semiotic concepts. This created a focus on the drawings' gender differences: while male students much more often seemed to portray the body from a distance, including its (partial) outline and the following pregnancy, the female students typically approached the conception narrative as an internal, cellular event. I introduced the drawings, organized into female and male students' folders. Our physical arrangement supported a rather co-creational, equal position to each other and to the drawings: rather than sitting opposite from each other, as in a conventional interview, we were situated side-by-side, thus both gazing at the laptop screen.

There were several reasons to view the drawings on a computer. First, the original pencil drawings were vulnerable when transported, and when handled with bare hands. Second, I wished to have the possibility of browsing among the drawings while easily 
maintaining their order. The third reason was related to the forthcoming artistic form: viewing the drawings on a screen, and generating our conversation in real time along with them, represented an idea for the animation and inspired me about which parts of the dialogues and drawings might later work together. The storyline had not yet been developed, however, as I had only decided to employ the medium of animation in reproducing the drawings. During the conversations the shifts from one drawing to another provided a rhythm, based on my sense of when each micro-narrative was completed. The role of surprise plays a key role in this improvisatory meaning-making, as the experts did not know what the next drawing would look like.

I decided to conduct two separate conversations to allow more attention for the interviewees' individual viewpoints, and (for instance) to avoid them adapting their responses according to the other's responses. The settings and preparations for these conversations were slightly different. I first conducted a dialogue of about 80 minutes with Robert, at his office at the university on January $30^{\text {th }}, 2013$. The second conversation lasted longer (more than 100 minutes); it took place in Fenna's living room on February $8^{\text {th }}$, 2013. The first conversation influenced the second one in that, for instance, I implemented several of Robert's insights in my own responses to Fenna, to set their professional viewpoints (artificially) in a dialogue with each other, and to be able to create later, in the animation soundtrack, the illusion of the three of us being in the same space at the same time. This means that while each individual comment is unmanipulated and kept in relation to the drawing that evoked it, the interaction between Fenna and Robert in the animation is fictional. Both conversations were transcribed verbatim and will be used in this article to illustrate chosen situations from the process.

I had never before invited collaborators to interpret collected data, even though I had previously worked with human participants in the medical schools, and incorporated their interviews in video-based artworks (Koski, 2013). I had known Robert since 2008 in relation to my former research proposal. Our conversation was characterized by our nonmedical viewpoints, although we had training in reading visual material. We both struggled with medical terminology, as well as the students' handwriting in the drawings, and often literally had to collaborate in trying to unravel the drawings' elements or intentions. In fact, considering the context in which the anatomical drawings were made, medical education, both Robert and I were outsiders while Fenna was an insider (see Lingard, Schryer, Spafford \& Campbell, 2007).

The project was my first collaboration with Fenna, after being introduced to each other through a mutual friend. Coming from two very separate disciplines, we did have differences of opinion related to the choice of the research focus and the form of output. While our viewpoints were professionally further apart than mine was from Robert's, we connected in ways that were not part of the conversation with him. Both of us being female, and having the organ system that was the topic of discussion, introduced a personal dimension to our discussion, such as the question: "do you have children?;" as well talking about us as women.

\section{The Animation Not to Scale at All}

The animation begins by inviting Fenna (as a physician) to draw her version of the female reproductive system. Whether or not the drawing is correct is left ambiguous; Kaisu asks her, "What is this, actually?" The question is picked up by Robert, whose reflection 
overlaps with the medical students' drawings, which appear one at a time. Robert reads the drawings as cultural icons of fertility; he draws comparisons with da Vinci and notes how the images simulate scientific aesthetics and portray conception as a competition.

The animation is in black and white. The students' drawings are re-created with a black line, with incidental black and white video shots in between them, reminding the viewer of the actual drawing situation, and the drawings' connection with an actual woman's body. The three collaborators interpret the students' intentions and thinking processes behind the drawings. After one third of the ten-minute narrative, the discussion revolves around the differences between the female and male students' drawings, and the possible explanations for these differences. While the conversation up until this point had been presented in a light tone of voice (including playful interpretations), the atmosphere from there on gains a serious quality. Fenna considers the drawings as the female students' vulnerable self-portraits, and she introduces the possibility that many of the students may have had negative sexual experiences in the past that made the exercise even more challenging for them. Kaisu is taken by surprise by this reading, as her preconceptions of the female medical students' had been that they were "sacred."

The final scene displays a variety of students' drawings on top of one another, repeating the choreography that emerges from the cultural-medical views of the female interior. This is accompanied by the collaborators' one-word associations about the drawings' shapes that were produced throughout the conversations, forming a rhythmical ritual.

\section{Making Meaning Collaboratively: Differences in the Male and Female Students' Drawings}

In this section we introduce the main viewpoints that emerged from our data interpretations, as performed by our professional roles and genders. In essence, these interpretations expand and generate possible reasons for my previous findings on the differences between the female and male students' drawings. The collaborative analysis here introduces more eyes and ears to explore the drawings' meanings; during the process we reminded one another of the viewpoints that we were not aware that we had been ignoring (Russell \& Kelly, 2002), thus reminding each other of our blind spots. Such reflexivity includes recognition and evaluation of our individual belief systems (Ahern, 1999), and making these transparent in the resulting animation.

Unlike in my initial analysis, the focus of the interpretations was not on the anatomical accuracy or the portrayed elements of the organ system. However diagrammatic the anatomical drawings may at first have appeared, during our conversations we viewed them as being semi-ambiguous "projective drawings." While the students' pictures refer to the same anonymous organ system, as projective drawings they involve variable expressive components such as pressure, proportions, and placement, as well as personal and cultural interpretations (Hammer, 1958). Consequently, the criteria of looking at and understanding the gender patterns in the drawings derived from three distinct aspects: 1) the female reproductive system as a cultural icon; 2) the relationship with the tradition of anatomical visualizations; and 3) the students' personal or emotional projections, together with emerging medical student stereotypes that we collaboratively identified. In addition, while generating these projections about the drawings and the 
students, we directly and indirectly told stories about ourselves (see Denzin, 2001, p. 25) by unveiling our personal experiences and worldviews.

Our interpretations produced various representations and metarepresentations of the drawings and the students. While the students' drawings of the female reproductive system are representations of the actual female body, our interpretations of these drawings are metarepresentations: they are public representations (utterances) of public representations (drawings) (Sperber, 2000, p. 3). Our discussion, however, expanded beyond observing what was actually drawn (public representations), to the students' thoughts and beliefs, including projections of their professional career perspectives, during which we were third-person "mind-reading" (Nichols \& Stich, 2003). We were, in other words, pretending to know what the students were thinking, and occasionally even taking the first-person role as a student. We thus considered the drawings as metarepresentations of the students' mental representations behind the drawings: "[he is] trying to think how a scientific image would look like."

Anatomical drawings as self-portraiture. While several of the drawings, more often by the male rather than female students, included a pregnant body contour as an illustration of the conception process, only one of these involved a facial expression of the pregnant woman. As smiling women are absent throughout the tradition of anatomical visualizations, most body outlines the students drew were faceless as well. Referring to one particularly impersonal body outline (Figure 2, on the left) Robert suggested that in order to become a good doctor, the student may need to introduce a face to the body, thus integrating the body and the person. Fenna, in contrast, having experience in medical practice, introduced an opposing viewpoint: the necessity for a medical professional to distinguish the person from his or her biology (Figure 3 ).

Robert: The difference between this portrayal of the whole body and the other on is that this is only a map, you know, the body is only outlined without hands, without feet, without a face actually, while the other one of course shows emotions, and actually depicts a person. [...] She might be a good doctor, but I think she needs to introduce the face.

Fenna: I think to be able to function professionally you have to uncouple the person and the biological parts, and by asking a woman to draw the female organs which are related to sex, which is a very emotional subject, it is less objective than [to] draw your foot or whatever. Then you pinpoint the more professional and personal, maybe, the vulnerable.

Some drawings involved visual indications of hesitation, whether it was because there was a fear of drawing poorly, making a technical mistake, or the topic itself. In this instance, Fenna "mind-read" what the female students might have experienced in a way that Kaisu had not: the reproductive system in relation to personal sexual experiences. More specifically, Fenna introduced the insight that many of the female students may have had negative sexual experiences (Figure 4). This insight was both crucial in increasing the emotional sensitivity of our projections of the drawings, and humbling for Kaisu because 

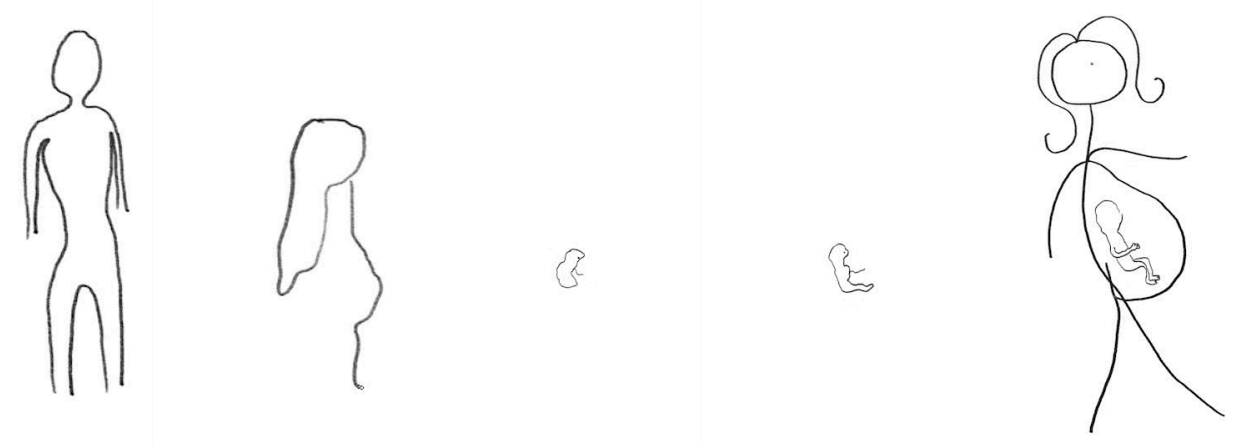

She might be a good doctor but I think she needs to introduce the face.
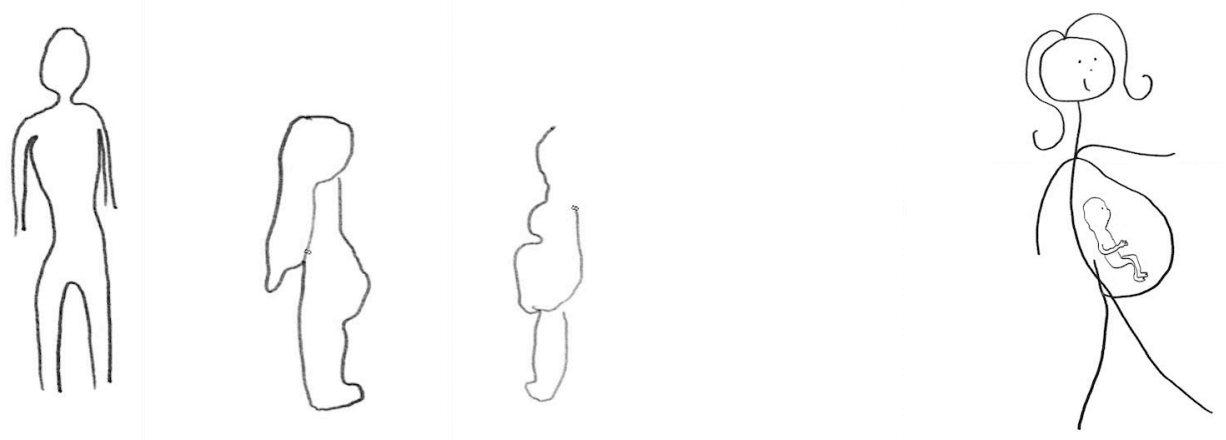

To be able to function professionally you have to uncouple the person and the biological parts

Figures 2 and 3. Still images from the animation Not to scale at all (Koski 2014) display the opposing viewpoints of the doctor and the art historian.

she had thus far dismissed such a distressing factor as potentially influencing the drawings (Figure 5). In the animation, this dialogue is displayed together with a drawing that moves along with the skin of a breathing female body.

Fenna: You have to take into account that many women who were asked to draw this drawing might have [had] a negative sexual experience. It could be rape, you know, at worst, or much less 
severe than rape, yet still an unpleasant experience.

Kaisu: Thank you for this insight, because maybe it tells how I can distantiate myself from the drawing because I wasn't even thinking of this possibility.

Fenna: No?

Kaisu: No, because [...] maybe with a different population [...] but for some reason I thought: female medical students are like ...

Fenna: They're sacred, yeah. Untouchable.
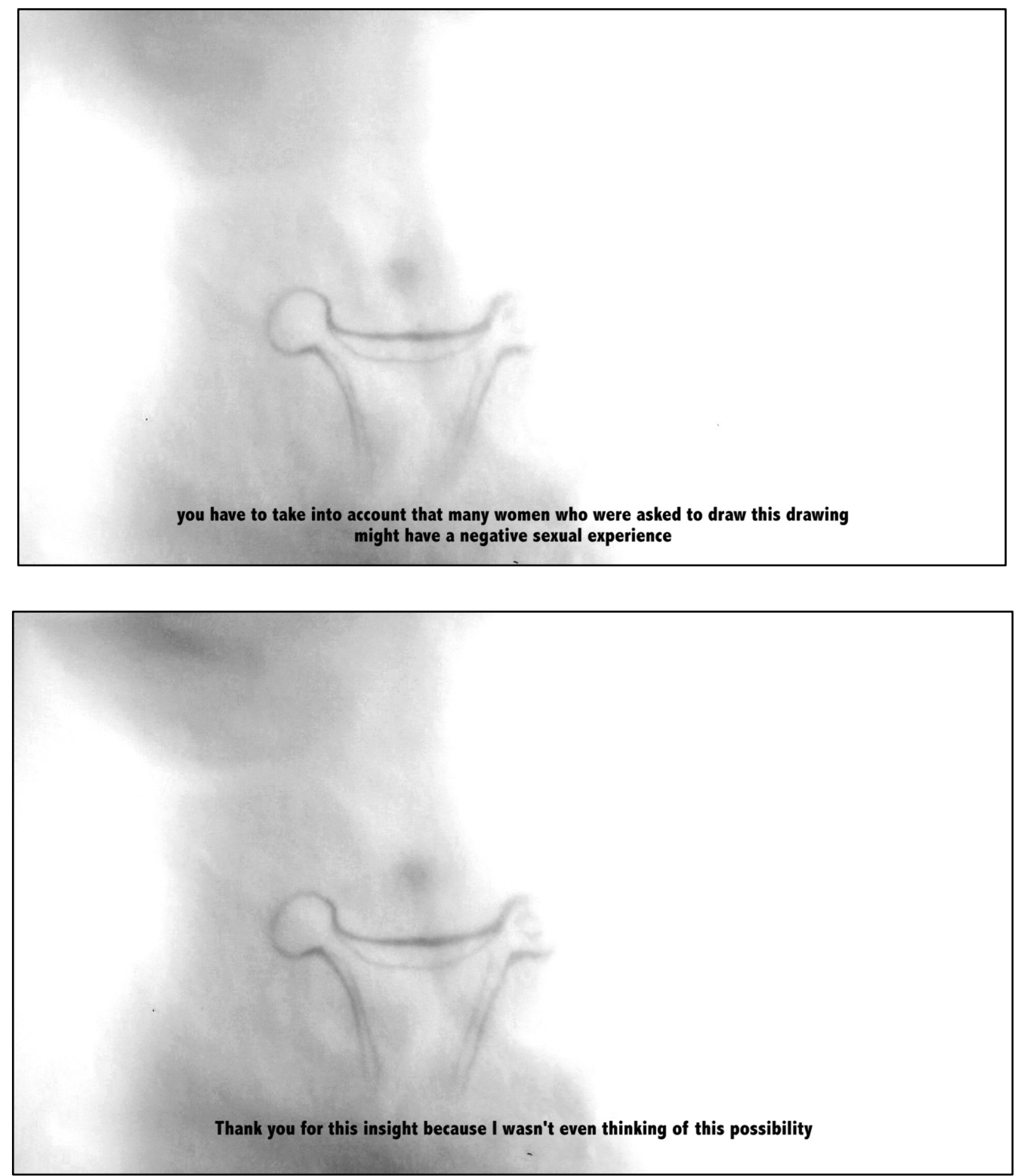

Figures 4 and 5 . The reproductive system in relation to personal sexual experiences. 
Robert had referred earlier to the possibility that female students chose more sterile expressions in their drawings to objectify the otherwise too-sensitive topic. Kaisu, on the other hand, did not consider the female drawings as self-portraits, until Fenna quite literally introduced this viewpoint. Furthermore, as many male students' drawings included the legs and hips of the female body (Figure 6), Fenna speculated that this perspective may have originated from their sexual experiences, as well as stereotypical pornographic imagery. Here Kaisu was confronted, and mildly embarrassed, by her preconceptions of medical students as not being subject to various aspects of sexuality: first by assuming that female medical students would not have had negative sexual experiences, and, later in the discussion, by assuming that male medical students would not watch pornography.

Kaisu: Because at this stage they still think it's my organ ...

Fenna: But it is! I still think it's my organ! [...] if you ask me to draw that drawing... I identify with that.

Kaisu: So it is a self-portrait of some kind?

Fenna: I would like to consciously decide what I show to you, and what would I rather keep to myself.

Kaisu: Male students commonly refer to the whole body, either its hips or legs because it's not a self-portrait. [...] It's the only organ actually you cannot relate to your own body. For men.

Fenna: Yeah, but why would that make you draw the legs? So if you would ask the female students to draw the male penis and whatever, would they draw legs and hips? I don't think so. [...] there is very different and much less attachment culturally, I think, towards the male reproductive system.

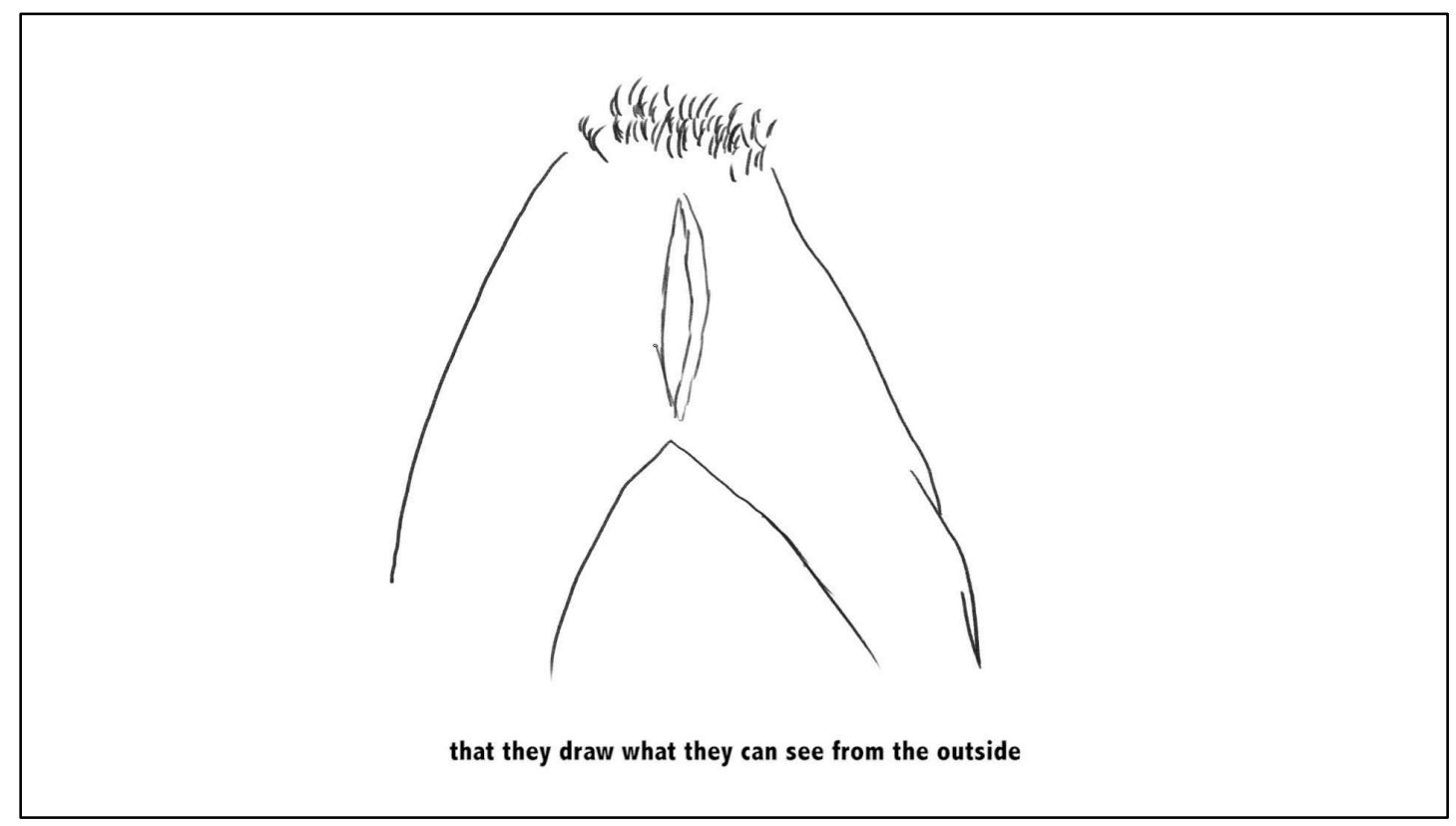

Figure 6. A male student's drawing of the female reproductive organs. 


\section{Improvisatory Interpretations: Entertaining the Potential}

In viewing the drawn shapes of the female reproductive system and the sperm cell as cultural icons, this project invited the participants to form playful associations. In this mode of looking at the drawings, we were distancing ourselves from the professional knowledge bases and the focus of the gender patterns in the drawings, and calling out improvisatory associations as metarepresentational narratives instead. In addition to reflecting on the drawings from a professional role, the project at that point embraced the idea that the researchers "do not stand apart from their own humanity while creating new understandings" (Russell \& Bohan, 1999, p. 404). In fact, in these instances we were momentarily talking out-of-character, disrupting the impression of professionals that we had previously established as being in-character (Goffman, 1959). I stimulated the improvisatory mode of talking, as I was calling out my own associations; in fact, choosing to emphasize my ignorance in what came from the drawings' meanings. Improvisation, however, does not mean loss of awareness of the research context, or merely saying the first thing that comes to one's mind. Following Montuori's (2003, p. 244) account of improvisation within academic contexts, the authors' playful associations on the drawings were embodied performances, which included ideas and moods that would have been absent if viewing the drawings and preparing the conversations beforehand. In addition, they required a willingness to take risks in order to perform such "diagnoses" of the drawings in the moment.

In the process of improvising, the intuitive right brain fantasies were invited to subside the linear left-brain reasoning (Hunter et al., 2002, p. 397). Instead of having fun at the expense of the drawings, though (let alone the students), generating humor was not the purpose in itself. Humor represents an inherent part of our humanity, and an organic by-product of a way of communication in which the potential and fictional narratives unravelled the drawings' status as cultural icons and medical student stereotypes. While being open to such experimentation, Fenna and Robert both regularly stepped in and out of the spontaneously created "storyworlds" by reminding both themselves and me that "this is of course speculation," that the associative playfulness was a temporary agreement for an alternative working consensus. Much as in musical improvisation, one person always leads a particular associative narrative and the others subsequently follow or contrast the gesture in some way.

Improvisatory associations performed out-of-character were organically interlaced with the "professional performance" sections in the conversations, as eventually was the case in the animation as well. It is thus not something that was used as a warm-up exercise to prepare for more serious topics, or to lighten up the atmosphere afterwards. To avoid too much self-awareness or interruption for the flow of the interview, no announcements were made beforehand that the interview would consist of particular modes of talk. Fenna and Robert were thus challenged to be flexible in maintaining and dropping the working consensus as professionals. Our physical positions next to each other seemed to aid the associative mode of talking: one is more easily caught up in fictional narratives when looking at a drawing and not being directly looked at or addressed with questions. This does not mean, however, that the narratives echoed or supported each other: we shared the mode of talking but continued to introduce different readings.

The students' drawings did not involve intentional humor themselves, apart from an incidental cartoonish drawing style: all students seemed to take the exercise seriously. This seriousness, though, combined with odd-shaped anatomical structures and overall 
naïve aesthetics, was heart-warming, and occasionally produced a certain kind of goodnatured laughter during the interpretations. Instead of suppressing these naturally rising reactions, we improvised short fictitious narratives of what could be embedded or hidden behind the drawings, entertaining the various potentials within. Due to different disciplinary backgrounds and personalities, it was not self-evident right away that we had found a similar register from which to talk. The improvisatory narratives required the conversational partner to accept and follow the direction that had been initiated, even if the invitation to join was a hypothetical or unlikely narrative.

Humour in collaborative meaning-making. In viewing the drawings, there were four different starting points to generate spontaneous metarepresentations, all of which stimulated humor for different reasons. First, many drawings were ambiguous in what elements of the organ system they aimed to portray; they represented a mystery of some kind, leading us to ask what we were actually looking at:

Fenna: I thought it was a woman! With two legs and a head and two arms.

Kaisu: It is! Because this is the head ... it is the first time l'm seeing it ... and it's like weight-lifting.

Fenna: Yeah. And we even have the labia. He's been there.

Kaisu: He's been there, he sees himself as part of this process. I mean look at the detail in the penis also. He has elaborated that. [Kaisu introducing Robert's viewpoint]

Fenna: Oh it's a penis. Is it a penis?!

Kaisu: What did you think it is?

Fenna: The vagina ... oh, it's a penis in the vagina. Right. No I thought it was the vagina wall, but there's a penis ... now I see it ... wow, yeah!

Second, humorous associations were made when the drawing involved an element that seemed totally obvious, likely not worth mentioning, or an element that was completely irrelevant to the task. These situations left us imagining why the student would include such an element. This wonderment at the students' motivations resulted in associations of student stereotypes, possible sexual orientations, medical sub-discipline interests, and other personal characteristics of the students: "She's much more a writer than a ... ," "Is he gay?," "He is going to be a radiologist."

Third, several drawings' elements surprised us in that we were faced with disbelief in our perception, questioning whether we actually correctly saw, for instance, that there was a $1 \mathrm{~cm}$ diameter hole in one paper. In such situations, we began generating narratives of what might have happened in the drawing situation. 
Robert: Is there an actual hole?!

Kaisu: It is, there's ... I don't know what he tried to do, but there's a hole.

Robert: That's interesting isn't it? [...] There is a kind of violence ...

Kaisu: It's drawn in quite an intense way anyway ...

Robert: Yeah, it is! There is some emotion here, in this drawing. And it's strange that there isn't really an entrance here. He crossed it out but, still, how does the sperm come in here?

Kaisu: Well how does the sperm come in here? I mean it's ...

Robert: With some violence anyway [laughter].

Fourth, humor and fictitious narratives in these improvisations arose also from a delight or astonishment of the aesthetic choices made by the students. There were, for instance, minimalistic or naïvistic aesthetics of the drawing- "I like the pubic hair"-or, for instance, an upfront pornographic aesthetic- "he's been there."

Fenna: Oh, that's a Picasso, eh?

Kaisu: There is something very touching about this.

Fenna: A nice little sperm in the middle. [laughter]

Kaisu: [...] the lonely sperm... [Kaisu introducing Robert's interpretation]

Fenna: It's not lonely. It's alone. [laughter] [...] Here I am, yeah.

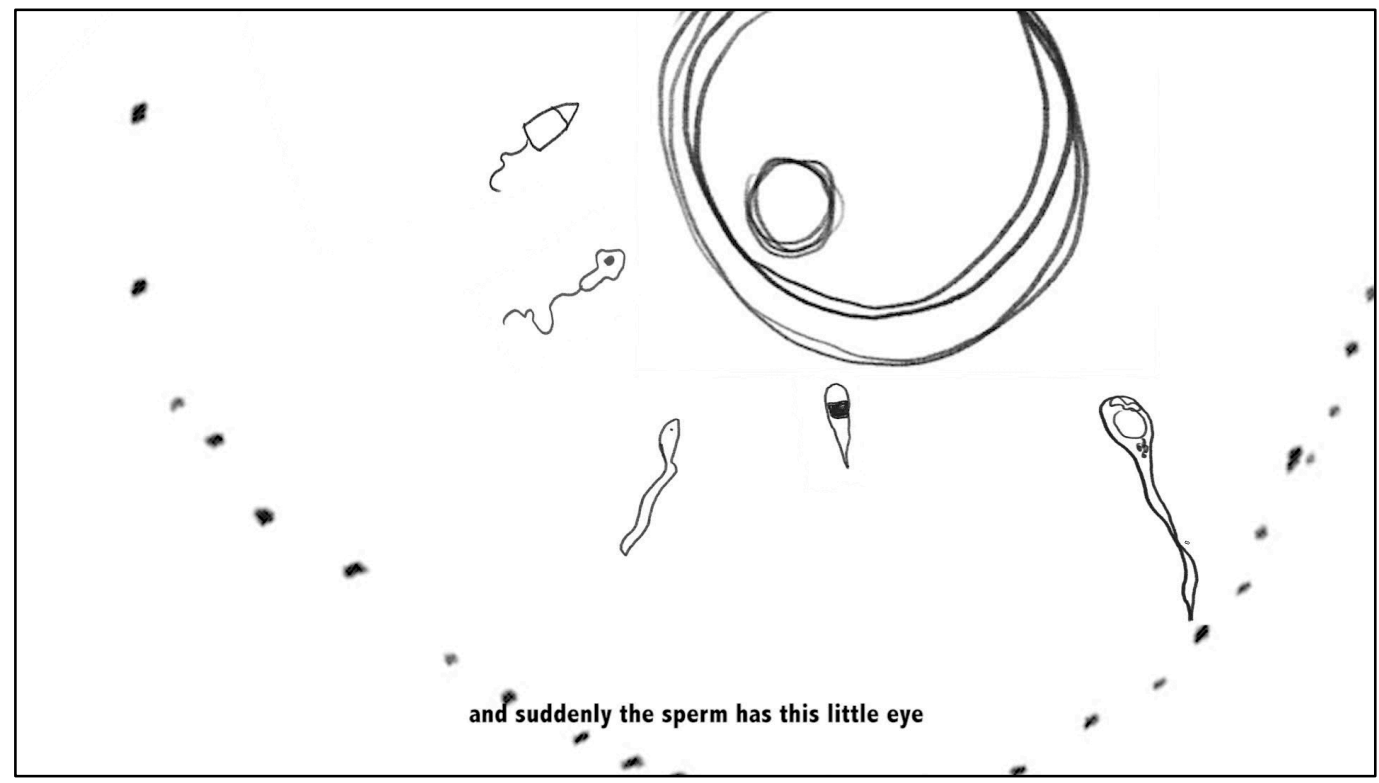

Figure 7. Sperm cells combined from different drawings approach an egg. 
While we were aware that the sperm does not feel lonely, we chose to entertain a fictitious metarepresentation of sperm as a character. Later in our conversation we encountered a sperm with an "eye" (Figure 7); even though we knew that the dark spot was not likely to represent an eye (but the nucleus), we chose to pursue such a narrative, to dramatize and humanize the elements in the drawings. Some of our readings parallelled the social metaphors for conception, according to which the sperm cell is active and the egg cell passive (Wagner, Elejabarrieta \& Lahnsteiner, 1995): the crowd of sperm in a student's drawing implied that "it's a competition, isn't it?," while an image of a "lonely" sperm cell made us wonder if "perhaps the female is not yet ready for it?" While I had initiated the associative mode of talking in order to generate versatility in the recordings for the animation, these sections increased the richness of the interpretations, as well as the transparency of our worldviews as interpreters. Due to their public nature in the arts-based outcome, however, the associations and the humor involved also resulted in ethical questions and discomfort between the collaborators.

\section{Emotional Discomfort in Collaboration: Irritation, Insecurity, Embarrassment}

Embarrassment and other forms of emotional discomfort are usually considered harmful in the context of academic research with human participants, and ethics protocols typically aim to ensure their absence. This discussion of our arts-based research project, however, introduces an alternative viewpoint. In this last section we distance ourselves from the actual data, and discuss three situations of the collaborative arts-based process, which challenge the conventional research ethics guidelines and power-relations, resulting in experiences of irritation, insecurity, and embarrassment for one or more of us. While the experiences did not represent severe distress or humiliation, they were still clearly unpleasant emotions, resulting from the arts-based nature of this project. These experiences are here viewed from the dramaturgic perspective: we discussed them in relation to the professional roles we performed, elaborating on how the working consensus of three professional "characters" deliberately and accidentally falls apart and is put back together again (Silver et al., 1987, p. 52).

Upsetting the working consensus as a physician. During the first data interpretation conversation, Robert had introduced me to an idea: to begin Fenna's interview by inviting her to conduct the same drawing task as the students. There was the expectancy that she would create an accurate representation of the female reproductive system and the conception process, primarily because she was a physician, but also because she had gone through the process of pregnancy as a mother. The drawing task came as a surprise to Fenna, right at the beginning of the interview. The resulting drawing turned out to involve an anatomical error, in which she located the site of conception as being in the uterus instead of in the fallopian tubes. This situation was obviously uncomfortable for Fenna, who was caught off-guard: when asked to draw from her medical knowledge, she failed to do so correctly. The situation involved discomfort for me, as well, because, somewhat surprisingly, I had knowledge to upset the working consensus of the doctor as the expert of anatomy (see Silver et al., 1987, p.54); in order to resolve the situation, I needed to share that knowledge with Fenna. I struggled with pointing out the mistake: one of my strategies in managing the situation was, in fact, to camouflage my evaluation in self-doubt. 
Kaisu: OK. Umm ... I mean you know more about this than I do, but I'm just going to ask ... does the conception, does the fertilization happen here?

Fenna: Yeah ... or?

Kaisu: Or in the fallopian tube?

Fenna: It depends, I think ... I think in the tube, yeah, I'm not sure ... but is it important?

Kaisu: It is important because l'm ... that's kind of the secondary outcome that I'm figuring out: the level of understanding of biology the students actually have.

Fenna: Oh, and maybe mine is lower. [laughter] I have to... can llook it up?

Fenna answered the key question about the drawing's accuracy with a counterquestion, pushing me to unveil the right answer. I subsequently used another strategy to manage Fenna's embarrassment, making an excuse for her mistake: "it's not totally fair because you are not a gynecologist." While this excuse was relevant, as Fenna is a hematologist, the point here is that I attempted to repair Fenna's failed performance as a doctor. Fenna, in turn, wanted to check the correct location of fertilization from an anatomy book, thus not accepting my anatomical knowledge right away. Her discomfort was obvious, as she even suggested pausing the recording when investigating (although I insisted on letting the recording run).

Fenna eventually admitted her mistake, using humor as a way to manage the error, even if it disrupted the working consensus of a medical professional. An anatomical error in a drawing in the context of an arts-based project is obviously inconsequential in the medical sense. Fenna, however, was invited to the project in part because of her professional capacity as a physician: a profession that is typically veiled by the myth of perfection (see Allman, 1998). I felt partly responsible for this disruption, and experienced a secondary embarrassment. I tried, against proper research ethics, a third strategy to make Fenna feel better, by intentionally misinterpreting the error, and thus suggesting a consensus founded on fiction, alien to my actual perception of the drawing (Silver et al., 1987, p. 52): "Well, we can agree that actually this indicates the fertilization and this is the [route of] travel." My concern here was that the incident may have cast a shadow on the forthcoming conversation about the actual students' drawings, while ideally it would have begun with an open mind. Artistically, however, the situation was very interesting. Thus, together with my secondary embarrassment, I also experienced (unexpressed) excitement that "something unexpected" had happened, incorporating part of this situation, in fact, in the opening scene of the animation (Figure 8). While this situation admittedly represented so-called "juicy stuff" in the data interpretation, since it had a great dramatic impact (Saldaña, 1998) to engage the audience, such a scene is equally essential as a platform for reflexivity, as well as a means to democratize the student-data interpreter relationship. 


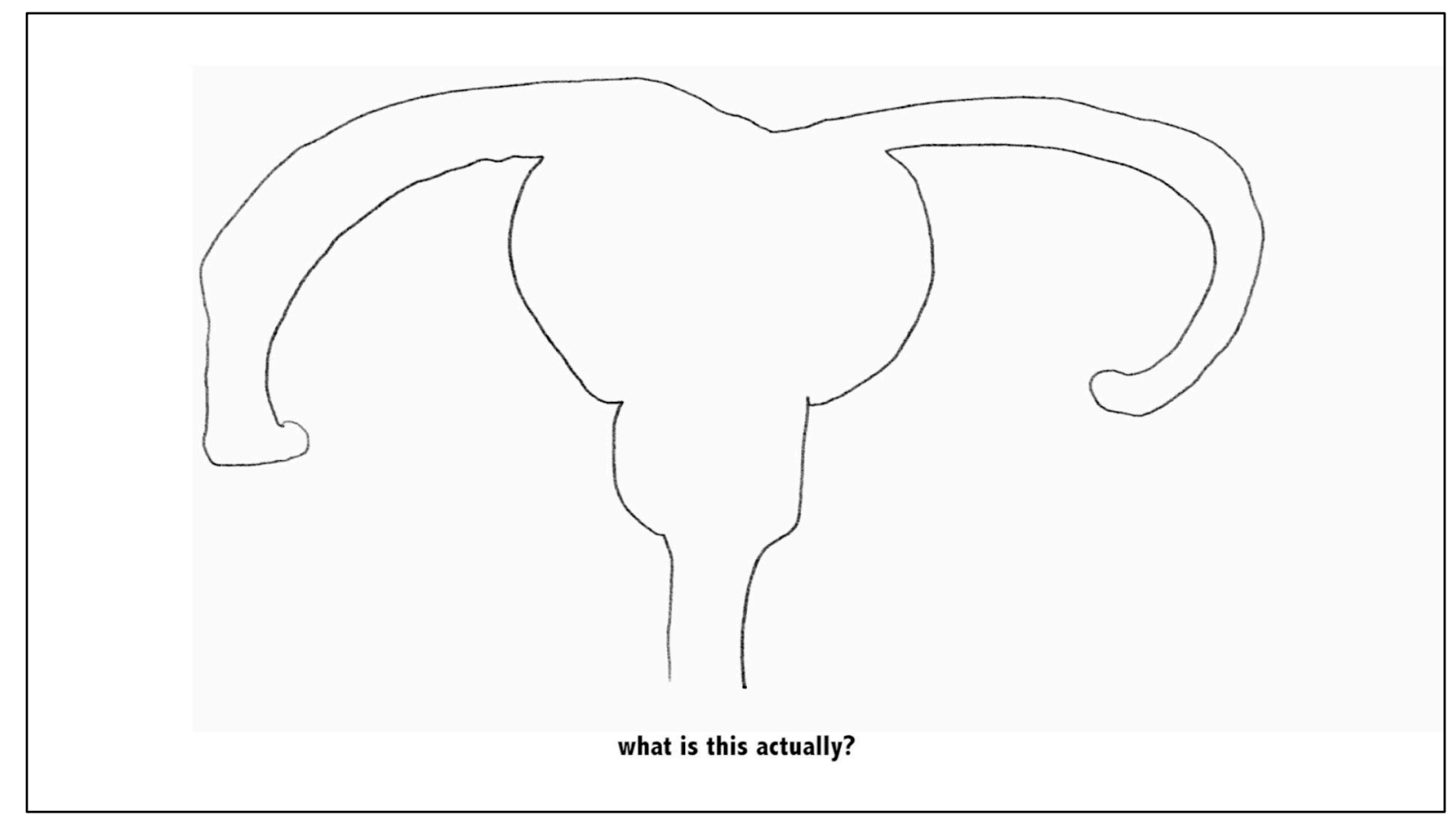

Figure 8. Physician's drawing of the female reproductive system as an opening scene of the animation Not to scale at all.

Insecurity in negotiating the parameters of the artwork. Opening up the creative process by inviting collaborators from different fields often adds to artists' vulnerability. This was especially the case during the last 30 minutes of the conversation with Fenna. I felt insecure when she wanted to know how the project was proceedingwhy I chose the topic in the first place, and suggested how to proceed with the materials.

Fenna: What will you, how will you, where will you go from here? [...] and what is it that you want to tell us, or show us? [...] I think you'll have to make some choices which one will I touch upon and which one will I leave out because it's just too much, I would think, to touch upon...

I felt insecure about my in-between role in this situation: there was a risk of being too considerate of the participants and ending up with boring artwork. There was also the risk of disappointing or embarrassing the participants by getting carried away with artistic ambitions only, although this seemed less likely than the first option. I thus felt that I had failed to perform the role of artist-researcher in the required way, in the lack of convincing scenarios for the reasons and directions of the project. My artistic performance was challenged also because the interview unveiled some of my rather stereotypical ideas about medical students, and blind spots in setting up the drawing exercise in the first place. While there was nothing odd about Fenna's concerns, I felt that my motivations and integrity, in fact, were questioned. I later reflected that this may have resulted from taking artists' rights to "do their own thing" for granted, as I normally work alone. I also started to question my reasons for the choice of topic, feeling reluctant to admit that it had to do with 
its controversy. In addition, part of my insecurity at that point was the fear that Fenna might not have granted permission to use her input for the artwork.

My usual intuitive, puzzle-like way of working-which allows the form of the artwork to arise from the collected material, instead of having an artistic form in which the materials would be embedded-challenged the rather linear and self-conscious expectancy for my process. It thus appeared that intuition and "not-knowingness" were in this instance not supporting my working consensus as an artist: the expected artist character in this collaboration was thus not a fuzzy character behind which I could conveniently escape in a lack of clear answers. The situation also did not allow me to lean on my alternative working consensus of a researcher or interviewer, because the power-relations were swapped by Fenna posing the questions. She thus unexpectedly resigned from her role as a physician, and introduced a curatorial character with involvement in the upcoming artistic decisions.

The discomfort in the situation was directly related to the arts-based nature of the project. The inherent uncertainty of the form of outcome, and the fact that I alone was going to work with the data, made the discussion difficult for both collaborators. We were, in fact, trying to negotiate the parameters for an as-yet non-existent artwork. If I had been intending to write an article on collaborative data interpretations only, the collaborators may have felt less vulnerable. Aspects such as tone of voice and laughter are conveyed more mildly and less vividly through written text than in spoken dialogue. In addition, as there was a necessity to represent the participants' viewpoints (rather than misrepresenting or aestheticizing them), I gravitated toward a documentary style and the use of actual voices of the collaborators instead of, for instance, using actors. Aside from being concerned about how we treated the students, however, Fenna was doubtful about my use of her voice in the animation. At the end of the interview, we negotiated on a license to use her comments.

Fenna: I'm still thinking, it feels a little bit vulnerable for me to let you use my voice but I think it'll be interesting [...] and I feel confident that you will...yeah I can trust you. [...] I think, yeah, you, you're sensitive enough to stay on the good side of the line.

Part of this negotiation, where Fenna eventually offered me the gesture of trust, forms the epilogue of the film, displayed together with the end titles. From a dramaturgical viewpoint, the data collection and dissemination may thus produce similar curves: Fenna's interview begins and ends with a challenging situation. "Staying on the good side of the line," however, is challenged in the project by publishing the animation in various contexts, such as educational institutes, research conferences, and arts platforms. While Fenna and I eventually established a good rapport about the finished animation, its appropriateness will be considered every time in relation to the viewing context.

Embarrassment during an animation viewing in the classroom. In December of 2014, I was invited to present a lecture to Robert's interdisciplinary art and science bachelor students, with Robert present in the classroom. As a part of this lecture, I showed the animation Not to scale at all. Before the viewing, I talked about the procedure of collecting the drawings and the ethical questions involved, and that the students may recognize some of the voices involved. At this stage the students did not know that their professor was a performer in the artwork. Immediately following the viewing, Robert commented on the viewing to the students by saying: "Well, that was embarrassing." At 
the time, in front of the class, I did not open up a discussion about the reason for the embarrassment, but I assumed it was because we had laughed at the drawings in the animation, and started to wonder if I had put Robert in a difficult position. As the initiator of a situation that caused him discomfort, I, again, felt secondary embarrassment.

When clarifying the situation later, however, it appeared that Robert's embarrassment had two different (and additional) reasons. Primarily, he felt that the animation positioned him centrally in the lecture, which he had intended to follow from the sidelines. In a certain way, there was a dissonance between Robert's two characters: he played one of the lead roles in the animation, but to date he had enjoyed a solid working consensus as a respectable professor of art history with the students. Secondly, there emerged some doubt about the material he had introduced earlier in his classes: due to the ethical considerations I had given before collecting the drawings, Robert felt that some of the other art and science projects he had introduced during the course may not have paid sufficient attention to ethics. Neither of these reasons for mild discomfort had anything to do with the actual content of the animation. Robert acknowledged, however, that some parts of the conversations in which we developed humorous associations, such as referring to the hole in the paper as a violent act, may have been absent had the conversation been conducted in the classroom. The humor was generated in a private conversation, and it appeared to be a sensitive aspect when it was re-contextualized in a piece of artwork.

The subject matter of the drawings obviously made the project more susceptible to emotional discomfort and humor than, for instance, the visualization of a foot. In addition, the student audience was significantly different from audiences in other platforms: what may have been experienced as embarrassing in the classroom may not have been so in a conference, or at a film festival. In addition, compared to a theater piece based on interview data, screen-based online-accessible animation involves fewer theatrical codes (such as buying a ticket and going to a special location) to distinguish its storyworld from the collaborators' everyday life. For similar reasons, Fenna has not viewed the animation with her students or medical colleagues. It seems too vulnerable to introduce such a different role, including personal aspects, of oneself in an environment in which one has a high status (professor-student, physician-patient, or director-employee), including peers who are not acquainted with the arts-based approach. While from a stereotypical artist's working consensus viewpoint- "you are all crazy, you can do anything," the project represents a serious attempt at a cultural documentary involving moral responsibility for a large number of participants, for the non-artist collaborators, the project is an unorthodox divergence from their actual practice.

\section{Discussion}

This article has discussed a collaborative meaning-making project involving an artist, a physician, and an art historian. It opened up the data interpretation process on medical students' anatomical drawings, introducing interpretations based on both the establishment of particular professional "characters," and a disruption of these roles in improvisatory associations. As a consequence of this flexibility in the collaborators' positions, the project resulted in various experiences of emotional discomfort. In fact, this article has deliberately exposed the data interpreters' discomfort-in Goffman's (1959) terms, the "back" regions or backstage of the conversations-and considers these to be essential dimensions and areas of meaning-making and reflexivity. These aspects also 
form necessary elements in creating thought-provoking, arts-based outcomes for the project, thus also influencing the preceding data collection and interpretation. There was thus a dual purpose in increasing the project's transparency and democracy, as well as in generating rich analysis of the drawings, including a range of emotions, for a compelling arts-based dissemination. While the audience of such artworks may be intrigued by someone's struggle in maintaining a particular working consensus, staging raw data of uncomfortable experiences challenges the collaborators to examine their tolerance for discomfort. In fact, none of the emotional discomfort or embarrassment was caused and experienced by one individual only, but the discomfort was always linked to, and shared in, collaborative relationships during both the arts-based data interpretation and the dissemination.

Setting the different professional viewpoints in a dialogue with each other, the data interpretation generated potential reasons behind the differences between the female and male students' drawings. While I initially thought the female students' diagrammatic drawings with processes on a cellular level pointed to their more fragmented and clinical view of the body, Fenna introduced a viewpoint in which the female students chose to portray a mere organ system, because adding reference to the whole body or a person would have made it too personal, given the sensitive topic of drawing. In addition, whereas I had considered male students' drawings with body outlines and legs as a consequence of them always viewing the female body from the outside, Robert saw how the male students actually saw themselves as active participants in conception. This, in turn, was contrasted with Fenna's hypothesis on the influence of pornography on the male drawings. The purpose here was not to arrive at one single most plausible interpretation, but to let them co-exist and resonate in each viewer and reader differently.

The arts-based approach of this project resulted not only in polyphonic interpretations, but in various experiences of discomfort for the collaborators as well. To begin with, I introduced an unexpected drawing task that Fenna failed to complete correctly. In another instance, when my motivations for the choice of topic were questioned, I was unsuccessful in answering the question convincingly. However, not all discomfort was caused by the performance as and interaction between our three initial characters, but it emerged from the multiplicity of our identities as well (Lingard et al., 2007, p. 505). For instance, as well as his performance as an art historian, Robert represented an educator later in the process. He was put in an uncomfortable position by viewing the arts-based outcome in front of his students. The absence of discomfort during our conversation, however, derived from Robert's acceptance of my choice of topic and the subsequent artwork development without questioning me. With this gesture of trust, supported by our longer collaborative relationship, Robert welcomed my invitation to join the improvisation, trusting it would lead to something meaningful.

In evaluating the conversation method developed in this project, questions arise about how democratic the setting was: Were we imposing our own narratives on students, who were silenced, without an opportunity to respond? Should all the collaborators have been involved in the artistic process of composing the data? It may have been more ethical to expose the data interpretation to be evaluated by the students who made the drawings, asking whether they feel that their drawings were appropriately interpreted and represented in the animation and in the articles. In terms of the collaborators' power relations, the project revealed that the non-artist collaborators may also have had preconceptions about what the art and arts-based outcomes should have been. While these different viewpoints can be discussed together, such an exchange often stays on a 
hypothetical level, that is, apart from the actual art practice. In the case of animation, for instance, the data ordering primarily took place through montage, which can be controlled by only one person at a time. The collaboration was thus not horizontal with peers (see Paulus, Woodside \& Ziegler, 2010), but rather was asymmetrical due to my artistic strategies and medium. In my way of working the narrative typically emerges from the act of editing, not before it, being a result of an improvisatory feedback loop between me and the recorded materials within a computer (software). In fact, I founded the entire project by considering the process of improvisational editing as the synthesizing force completing the polyphonic research process. It would be very difficult to include a research collaborator in this immersive dialogue with the data, even if there were a practical way that it could be arranged due to its time-consuming nature. Furthermore, improvising in someone's presence would alter the process and likely add the pressure of "performing." In this project, the collaborators thus took a leap of faith in donating their recordings to me to work with them alone; thankfully, with an end result with which all three were satisfied.

The asymmetry in the collaborators' roles was balanced through other aspects than artwork composition: both Fenna and Robert were invited as experts in fields of which I was "ignorant;" they were empowered when being relied upon in their roles as experts (Berger \& Malkinson, 2000). Yet, seen from another viewpoint, the role of an ignorant person is also a way to use power, allowing one, for instance, to ask taboo questions without restrictions. In addition, being ignorant is a temporary role; after being involved in medical education research for several years now, I may need to reconsider my "ignorance" in this field.

The collaboration in this project has enriched us not only by becoming familiar with each other's worldviews, but it has, sometimes awkwardly, also mirrored those of our own, asking us to reconsider some of our viewpoints. The resulting experiences of discomfort have deepened our understanding of interdisciplinary processes, and our appreciation for the expansion of our performative repertoires as researchers. The collaboration succeeded in this project because we managed to relate to our discomforts with humorto the degree of being comfortable with exposing them in this article, and because these were in the end outweighed by the inspiration and by new ideas. We are already envisioning new collaborative projects, this time potentially initiated by Fenna or Robert, and we are curious about whether similar questions will remain the source of differences, and of whether we will encounter even more kinds of fruitful challenges in future collaborations.

\section{Acknowledgements}

Thanks to all the first-year medical students who participated in this arts-based inquiry at the Plymouth University Peninsula School of Medicine. I also wish to warmly thank Dr. Sam Regan de Bere for supervising and facilitating my postdoctoral fellowship in 2012. This postdoctoral research project (2011-2013) was financially supported by the Academy of Finland.

The animation Not to scale at all (2014) received financial support from the Arts Promotion Centre Finland and the University of Lapland. 


\section{References}

Ahern, K. J. (1999). Ten tips for reflexive bracketing. Qualitative Health Research, 9(3), 407-411. DOI: 10.1177/104973239900900309

Allman, J. (1998). Bearing the burden or baring the soul: Physicians' self-disclosure and boundary management regarding medical mistakes. Health Communication, 10(2), 175-197. DOI: 10.1207/s15327027hc1002_4

Berger, R., \& Malkinson, R. (2000). "Therapeutizing" research: The positive impact of research on participants. Smith College Studies in Social Work, 70(2), 307-314. DOI: $10.1080 / 00377310009517594$

Casey, B. (2009). Arts-based inquiry in nursing education. Contemporary Nurse, 32(1-2), 69-82. DOI: 10.5172/conu.32.1-2.69

Cox, S. M., Lafreniere P., Brett-MacLean, P., Collie K., Cooley, N., Dunbrack, J., \& Frager, G. (2010). Tipping the iceberg? The state of arts and health in Canada. Arts \& Health 2(2). DOI: 10.1080/17533015.2010.481291

Denzin, N. K. (2001). The reflexive interview and a performative social science. Qualitative Research, 1(1), 23-46. DOI: 10.1177/146879410100100102

Frank, A. W. (2005). What is dialogical research, and why should we do it? Qualitative Health Research, 15(7), 964-974. DOI: 10.1177/1049732305279078

Goffman, E. (1959). The presentation of self in everyday life. Garden City, NY: Doubleday.

Gray, J., \& Kontos, P. (2015). Immersion, embodiment, and imagination: Moving beyond an aesthetic of objectivity in research-informed performance in health. Forum Qualitative Sozialforschung / Forum: Qualitative Social Research, 16(2). Retrieved from: http://www.qualitative-research.net/index.php/fqs/article/view/2288

Hammer, E. F. (1958). Expressive aspects of projective drawings. In E. F. Hammer (Ed.), The clinical application of projective drawings, (pp. 59-79). Springfield, IL: Charles C Thomas Publisher.

Hodgins, M., \& Boydell, K. (2013). Interrogating ourselves: Reflections on arts-based health research. Forum Qualitative Sozialforschung / Forum: Qualitative Social Research, 15(1). Retrieved from: http://www.qualitativeresearch.net/index.php/fqs/article/view/2018

Hunter, A., Lusardi, P., Zucker, D., Jacelon, C. S., \& Chandler, G. (2002). Making meaning: The creative component in qualitative research. Qualitative Health Research, 12(3), 388-98. DOI: 10.1177/104973202129119964

Koski, K. (2012). Ethics and data collection in arts-based inquiry: Artist-researcher embedded in medical education. International Journal of the Creative Arts in 
Interdisciplinary Practice 11(June). Retrieved from:

http://www.ijcaip.com/archives/IJCAIP-11-paper4.html

Koski, K. (2013). As-if the patient were in the classroom: Video-based enquiry into the absent body in medical education. Journal of Applied Arts \& Health, 4(2), 207-222. DOI: 10.1386/jaah.4.2.207_1

Koski, K. (2014). Mapping the female reproductive system: Arts-based inquiry of medical students' anatomy drawings. Studies in Material Thinking, 10(1). Retrieved from: https://www.materialthinking.org/papers/143

Lingard, L., Schryer, C. F., Spafford, M. M. \& Campbell, S. L. (2007). Negotiating the politics of identity in an interdisciplinary research team. Qualitative Research, 7(4), 501-519. DOI: 10.1177/1468794107082305

Lehmann, H-T. (2006). Postdramatic theatre, [K. Jürs-Munby, Trans.] New York: Routledge.

Martin, E. (1992). Medical metaphors of women's bodies: Menstruation and menopause. In E. Martin (Ed.), The woman in the body, (pp. 15-41). Boston, MA: Beacon Press. DOI: 10.1525/maq.1989.3.3.02a00090

Montuori, A. (2003). The complexity of improvisation and the improvisation of complexity: Social science, art and creativity. Human Relations, 56(2), 237-255.

DOI: $10.1177 / 0018726703056002893$

Nichols, S., \& Stich, S. P. (2003). Mindreading: An integrated account of pretence, selfawareness, and understanding other minds. Oxford, UK: Clarendon Press.

Paulus, T. M., Woodside, M., \& Ziegler, M. F. (2010). "I tell you, it's a journey, isn't it?" Understanding collaborative meaning making in qualitative research. Qualitative Inquiry, 16(10), 852-862. DOI: 10.1177/1077800410383124

Riessman, C. K. (2003). Narrative analysis. In M. S. Lewis-Beck, A. Bryman \& T. Futing Liao (Eds.) The sage encyclopedia of social research methods, (pp. 705-709). Sage Publications. DOI: http://dx.doi.org/10.4135/9781412950589

Russell, G. M., \& Bohan, J. S. (1999). Hearing voices: The uses of research and the politics of change. Psychology of Women Quarterly, 23(2), 403-418.

DOI: 10.1111/j.1471-6402.1999.tb00371.x

Russell, G. M. \& Kelly, N. H. (2002). Research as interacting dialogic processes: Implications for reflexivity. Forum Qualitative Sozialforschung / Forum: Qualitative Social Research, 3(3), Retrieved from: http://www.qualitativeresearch.net/index.php/fqs/article/view/831/1806

Saldaña, Johnny. (1998). Ethical issues in an ethnographic performance text: The "dramatic impact" of "juicy stuff." Research in Drama Education: The Journal of Applied Theatre and Performance, 3(2), 181-196. DOI: 10.1080/1356978980030205 
Silver, M.; Sabini, J.; \& Parrott, G. (1987). Embarrassment: A dramaturgic account. Journal for the Theory of Social Behavior, 17(1), 47-61. DOI: 10.1111/j.14685914.1987.tb00087.x

Sperber, D. (2000). Introduction. In D. Sperber (Ed.), Metarepresentations: $A$ multidisciplinary perspective (pp. 3-13). Oxford, UK: Oxford University Press.

Wagner, W., Elejabarrieta, F., \& Lahnsteiner, I. (1995). How the sperm dominates the ovum - Objectification by metaphor in the social representation of conception. European Journal of Social Psychology, 25(6), 671-688.

DOI: $10.1002 /$ ejsp.2420250606 